\title{
The Path Forward: Conservation of Climate Change-Affected Breeding Habitat of Red- crowned Cranes near Zhalong Reserve, China
}

\author{
Minghao Gong ${ }^{1 *}$, Shiliang Pang ${ }^{2}$, Zhongyan Gao ${ }^{2}$, Wanyu Wen ${ }^{1}$, Ling Zhang ${ }^{3}$, \\ Gang Liu ${ }^{1}$, Huixin $\mathrm{Li}^{1}$, Fawen Qian ${ }^{4}$ and Wenfeng Wang ${ }^{2}$ \\ ${ }^{1}$ Institute of Wetland Research, Beijing Key Laboratory of Wetland Services and \\ Restoration, Chinese Academy of Forestry, Beijing 100091, China \\ ${ }^{2}$ Zhalong National Nature Reserve Management Bureau, Qiqihar 161000, China \\ ${ }^{3}$ China Wildife Conservation Association, Beijing 100714, China \\ ${ }^{4}$ Institute of Forestry Ecology, Environment and Protection, Chinese Academy of \\ Forestry, Beijing 100091, China
}

\begin{abstract}
A B S T R A C T
The endangered red-crowned crane (Grus japonensis, RCC) has the smallest population of all Chinese cranes, and is also susceptible to climate change because of its large body size, short migration distance, and specialized diet. We examined climate change-induced RCC habitat shifts and suggested some purposeful, resolute and crucial improvements needed to protect appropriate areas that ensure the RCC's long-term survival. Based on monitored data of nesting locations and climate variables gathered from 2014 to 2017 around Zhalong Reserve on the Songnen Plain in northeast China, we used four General Circulation Models in Maxent modeling to project changes, including suitability and fragmentation, in RCC breeding habitat up to the year 2050. Based on climate change, we predicted a decline in 2050 of suitable and sub-suitable habitat from the current $26.2 \%$ to $14.3 \%-19.7 \%$ in the study area, but an even larger loss (from $71.3 \%$ to $27.3 \%-32 \%$ ) of suitable habitat in Zhalong Reserve. The predictions also showed a northward movement of RCC habitat and a loss of current suitable habitat southeast of Zhalong Reserve, resulting in a discrepancy between future habitat areas and currently protected areas. In addition, climate change will further fragment RCC habitat, thus decreasing habitat suitability and carrying capacity, especially within Zhalong Reserve. Our study indicated that the most suitable breeding habitat is currently restricted to the Reserve. This finding partially explains that the low rate of RCC population growth is likely because of the limit of RCC's expansion due to spatial patterns of suitable habitat. We confirmed that temperature, rather than precipitation, had the most impact on RCC breeding. To cope with climate change, we recommend that new refuges be designed within the study area and the transformation of wetland to farmland in the area be banned. Also, organic agriculture methods and crop species that consume less water than rice should be adopted to mitigate the adverse climate changes that accompany global warming and will contribute to RCC habitat degradation.
\end{abstract}

\section{INTRODUCTION}

$\mathrm{C}$ limate change may result in habitat loss or fragmentation and may cause shifts in population ranges and phenological changes that degrade species fitness at habitat and genetic levels (Parmesan, 2007; Brook, 2008; Peacock, 2011). Global mean surface temperatures have been increasing since the late 19th century, with 0.2 to $0.3{ }^{\circ} \mathrm{C}$ increases over the past 40 years (Nakićenović and Nebojša, 2000). Many birds in Britain had moved farther north an average of $18.9 \mathrm{~km}$ during a 20-year span (Thomas and Lennon, 1999), and some North American

\footnotetext{
* Corresponding author: gongmh2005@hotmail.com 0030-9923/2021/0002-0733 \$9.00/0

Copyright 2021 Zoological Society of Pakistan
}

birds had experienced significant abundance shift with the average velocity of distribution centroids by 5.89 $\mathrm{km} \mathrm{yr}^{1}$ (Huang et al., 2017). Climate change projections indicate that species' range shifts over the next century will likely be significant (Hole et al., 2009), especially at high latitudes and in the northern hemisphere (Rubolini et al., 2010; Bitterlin and Buskirk, 2014). Climate change has already caused widespread alterations to species populations and ecological communities (Roberts et al., 2014). Temperature is the dominant abiotic factor directly affecting insect phenology (Bale et al., 2002), thus also making insectivorous birds significantly sensitive to temperature change, even more so than to precipitation (Pearce-Higgins et al., 2015). Higher temperatures may impact the energy birds expend to maintain homoeostasis (Both et al., 2009). Temperature changes could have 
significant implications on the phenology and life histories of migratory species, as well as on their food choices (Peñuelas and Filella, 2001; Heimonen et al., 2015), such as when the arrival of migratory species coincides with peak food availability (Both et al., 2009; Thackeray et al., 2010).

Migratory species are sensitive to environmental changes and are considered objective indicators of global change (Takuji et al., 2016). Range-restricted species are particularly vulnerable to climate change because they often have poor dispersal abilities and limited food resources. Thus, they have been identified as species with immediate and high probabilities of extinction caused by recent climate change (Parmesan, 2006; Crabtree and Ellis, 2010). In general, avian phenology is sensitive to climate change, especially given certain characteristics of body size, diet, and migration distances (Hedenström, 2006; Lehikoinen et al., 2010). With its large body size, the red-crowned crane is one such species affected by climate change because of both its absolute need of Phragmites-dominant vegetation to provide its specialized dietary and habitat requirements (Li and Yang, 1999; Su and Zhou, 2012) and its short migration distance, which is intra- continental (Takuji et al., 2016).

The RCC has the smallest population of all the Chinese crane species and is a globally endangered species, listed in the Convention on Migratory Species (CMS) Appendix 1 and CITES Appendix 1 (IUCN, 2012). It is also a first-level protected species in China (Ma and Tang, 1998; Wang, 2011). The RCC was found in 2 separate populations: the continental and the island populations (Su and Zhou, 2012). The island population resides in the southeast and northeast of Hokkaido, Japan, and is non-migratory (Masatomi et al., 2001; Masatomi et al., 2007). The continental population is migratory, breeding in northeast China and far southeast Russia from March to October. From October to March they reside on the Yellow Sea coast in eastern China and the central section of the Korean Peninsula (Johnsgard, 1983; Ma et al., 2009). This species faces serious threats from habitat loss and deterioration, and habitat fragmentation. Its population has declined sharply and estimates show only 1800 individuals remaining (Su and Zhou, 2012). The RCC is a phragmites-dependent species in summer and prefers large and integrated phragmites patches in a marsh. Containing a large phragmites patch, the Zhalong National Nature Reserve is the largest breeding ground for the migratory RCC population. Almost 300 RCCs, or onesixth of the total population, breed in the Zhalong Reserve (Wang, 2011; SFA, 2014).

Climate change is rapidly becoming one of the main threats to biodiversity. Indeed, species are already responding to climate change by shifting their distribution, and this may eventually cause spatial mismatching among population ranges, suitable habitats, and locations of protected areas (Santangeli et al., 2016). Yet, as RCC is a species likely impacted by climate change, there is a lack of knowledge of climate change-induced RCC habitat shifts. These knowledge gaps have resulted in two limitations to RCC conservation: 1) no clear information of RCC habitat spatial patterns for conservation adminstrators to use to allocate resources and staff during the breeding season and 2) no plans and procedures for coping with the effects of future climate change. Therefore, based on monitoring of both RCC spatial utilization and climate variables, this study focuses on RCC habitat in and around the Zhalong Reserve on the Songnen Plain. The aim is to expose potential dynamics induced by future climate change in order to 1) understand possible spatial pattern and suitability shifts in RCC habitat, given climate and economic scenarios; 2) identify crucial areas in need of protection and update the design of protected areas to ensure RCC's long-term survival while responding to climate change; and 3) provide suggestions for local cultivation methods based on climatic effects and RCC long-term survival.

\section{MATERIALS AND METHODS}

\section{Study area}

Our study area, in the heart of the Songnen Plain, covered 2,938,126.1 ha, including the Zhalong Reserve in Qiqihaer, China (Fig. 1). Established in 1987, Zhalong Reserve is the largest breeding ground for RCCs migrating between Zhalong and the Yellow Sea coast of China. Also, some smaller groups of RCC were present in suitable habitat on the Songnen Plain outside the Reserve and downstream of the Wuyuer River. This area includes the Nen River catchment, which contains extensive marsh land and Phragmites, thus making it a favored area of RCCs. The entire area is a sub-temperate zone with a continental semiarid and arid monsoon climate. The study area was $140 \mathrm{~m}$ above sea level and relatively isolated by raised land to the east, north, and west with 2 railways (Qiha Line and Qibai Line) and 2 highways passing through it. Because of its importance for migratory species, wetland habitat, and biodiversity, Zhalong Reserve was listed as the first Wetland of International Importance in China under the Ramsar Convention in 1992 (Ramsar, 2018). An additional RCC refuge, Wuyuerhe National Nature Reserve, established in 2006, is adjacent to the north edge of Zhalong Reserve. The study covered Qiqihaer, Gannan, Fuyu, Daqing, Duerbote, Tailai, and Longjiang cities in Heilongjiang province. As part of Songnen Plain 
in North China, this area is a traditional area of agricultural production and has been designated a grain base by the Chinese central government (Chen and Zhao, 2008; Zhang et al., 2012).

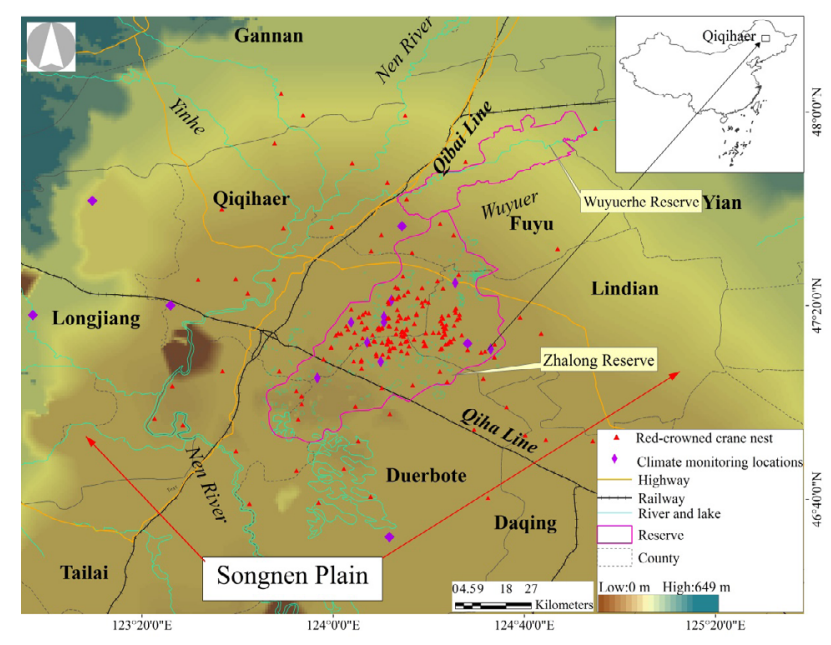

Fig. 1. The Songnen Plain study area including the Zhalong Reserve. Inset shows the study area in northeast China.

\section{RCC presence data}

Most cranes are territorial and depend on food resources within their territory. To satisfy trophic needs during breeding, monogamously mated RCC pairs spend most of their feeding time near the nest, while maintaining home range fidelity (Zou and Wu, 2009; Brown, 1969). RCC pairs tend to build their nests around the location of their previous years' nests when habitat changes occurred (Li and Zhao, 1991). So, we recorded nesting locations to reflect both RCC presence and their use of space. Because of their long-term annual monitoring programs and their intimate knowledge of the RCC population, the Reserve staff easily identified RCC nest locations. We located 175 RCC nests in Zhalong Reserve by doing line transect line surveys during routine RCC monitoring from 2014 to 2017. In addition, we obtained 37 RCC nest locations outside of the Reserve but within the study area by conducting faceto-face interviews of local, official wildlife protection staff and residents. Because most RCCs nests in marsh, their nests were difficult to locate using the Global Positioning System. Therefore, we marked each nest location on a Google Earth map and read their latitude and longitude locations from the map.

\section{Environmental variables}

Our study included both ecological and anthropogenic variables. We obtained river, lake, and marsh data from the Second National Wetland Survey performed by the
Chinese State Forestry Administration (SFA, 2014), and Zhalong Reserve. That data was supported by satellite images (Landsat 5) which was used to develop a vegetation map of dominant species (i. e., Phragmites australis, Deyeuxia langsdorffii, Carex lasiocarpa, and Aneurotepidimu chinense) in the study area. Elevation data in GIS layers were gleaned from a digital elevation model based on 1:50,000 scale topographic maps obtained from the Chinese Academy of Sciences (Geospatial Data Cloud). Regional anthropogenic threats to RCCs included roads, agriculture, and human settlements. To meet data format requirements for modeling, all line and spot data, such as roads and settlements, were transformed to create a raster layer by using EucDistance analysis in Arcgis 10.0 (Esri, Redlands, CA, USA), thus transforming the binary data into continuous data. The data for these variables were collected from the National Geomatics Center of China and the Zhalong Reserve Administration Bureau.

\section{Climate data}

We applied two sets of climate data in our study. One, compiled using monitoring data gathered by us, was used to identify current habitat suitability. The second, drawn from the Intergovernmental Panel on Climate Change (IPCC; WorldClim Data set) outlines climate predictions we used to project future RCC habitat (Hijmans et al., 2005; Parry et al., 2011). Given the expiration date (1990) of the IPCC's current climate data and to better target real time current climate conditions, we set up 9 meteorological recording spots within Zhalong Reserve to monitor bioclimatic variables from 2016 through 2017, and compiled those variables annually into current bioclimatic variables that coincided with all 19 climate parameters used by the IPCC, such as annual mean temperature, annual precipitation, maximum temperature of the warmest month, and so on. Then, together with additional climate data obtained during the same period from seven national monitoring stations (China Meteorological Administration) within the study area, we interpolated GIS layers of current yearly climate data to a resolution of $30 \times 30 \mathrm{~m}$ in our study area using Anuspline 4.3 with latitude, longitude, and elevation variables (Hong et al., 2005; Liu et al., 2008).

Future climate data used to predict habitat shifts were derived from projections of climate scenarios released by the IPCC (World Clim, 2018). To make the projections more immediate and applicable to crane conservation, we only modeled habitat under climate change scenarios from the present up to year 2050. Because there are 19 General Circulation Models (GCMs) and four Representative Concentration Pathways (RCPs; RCP2.6, RCP4.6, RCP6, RCP8.5) of greenhouse gas concentration in each GCM used by the IPCC, it is difficult to project changes in 
every GCM and RCP combination. Therefore, within the objectives of this paper and based on previous climate change-related wildlife habitat studies, we adopted four GCMs: BCC-CSM1-1(BC), CCSM4 (CC), HadGEM2-ES (HE), and MPI-ESM-LR (MP) to project probable climate change shifts (Tuanmu et al., 2013; Li et al., 2014; Gong et al., 2016). Since agriculture is the major industry in this area and it has been designated a base of grain production in China, large-scale, industrial projects have rarely been implemented. Moreover, considering Zhalong's Ramsar designation as a wetland of international importance, we concluded that levels of future greenhouse gas emissions will most likely remain low. Therefore, because of $\mathrm{CO}_{2}$ and $\mathrm{CH}_{4}$ emissions generated by agricultural activities (e.g., plowing and fertilization) inherent to grain cultivation, the lowest emission scenario, RCP 2.6 may be too optimistic to reflect actual climate dynamics in the area. Moreover, RCP 8.5 is probably not applicable to agricultural areas. So, as a low emission-oriented economy model, we adopted RCP 4.5 as the most likely scenarios to reflect future climate change in our study area, especially when including wetland conservation.

The IPCC climate data resolution was 30 second (about $900 \mathrm{~m}$ ). To spatially match the climate data that we interpolated, we set modeling data resolution to $30 \times 30 \mathrm{~m}$. Therefore, before modeling we had to convert the IPCC data into a raster with a resolution of 30 meters. To ensure that all GIS data matched, geospatial data was based on the Universal Transverse Mercator grid system using the World Geodetic System 1984 model as the reference.

\section{Habitat modeling}

We used Maxent (Phillips and Dudík, 2008) to identify current habitat suitability and habitat shifts in 2050. Maxent is typically used to model the impacts of climate change on habitat suitability by using presenceonly data, habitat variables, and climate variables (Gallagher et al., 2013). Combined with current environmental variables and species occurrence, we used Maxent to project habitat and its changes and to predict species distribution, assuming that species presence would be drawn from probable habitat (Phillips, 2008). In our study, species occurrences were all nesting locations indicating RCC presence. The environmental variables were vegetation, rivers, lakes, elevations, current and 2050 climate variables, and the main anthropogenic threats, such as roads and human settlements. Considering our study's aim and for convenience, we based habitat projections on the following assumptions: 1) Climate change will be the principal facilitating factor of RCC habitat shifts in 2050; 2) To reduce the uncertainty of modeling results, other environmental variables (e. g. Phragmites, vegetation, lakes, rivers) will remain stable in the short term; 3) Based on a recent human population decrease in northeastern China (Li and Xiao, 2015), anthropogenic variables, such as roads and communities, will likely remain static (Chen and Zhao, 2008).

To improve model performance, we used both 10,000 background points for modeling and different random subsamples (70\% training and 30\% test data) to calculate Area Under the Curve (AUC) test values. The AUC value is widely used as an indicator of a model's ability to discriminate between suitable and unsuitable habitat (Dan and Seifert, 2011). Our models were considered reliable when AUC $>0.75$ (Rebelo et al., 2010). The importance of habitat variables was evaluated based on contribution and permutation importance, and the higher a variable's value was, the more important the variable will be.

\section{Habitat suitability, shift, and fragmentation}

We ran the Maxent model with both current and future climate and environmental variables to project current habitat suitability, as well as the changes expected by 2050. Given that the habitat projected by Maxent modeling was a raster with a continuous habitat suitability index, all current and future habitats were classified into categorical data for further spatial analysis. Because the range of habitat suitability index was between 0 and 1 , we needed a set of thresholds for the habitat classification index. In our models, RCC presence was indicated by nests, so we used the proportion of nests to establish the levels of habitat suitability. Based on previous identifications of wildlife habitat suitability (Wood and Dragicevic, 2007; Xu, 2009), we set the threshold values of our habitat suitability classification index as follows: suitable, habitat containing $70 \%$ of the crane nests; sub-suitable, habitat containing $20 \%$ of crane nests; and normal, the remaining habitat. Then, to meet the aforementioned criteria, we identified a set of thresholds of suitability values to categorize current habitat into suitable, sub-suitable, and normal habitat. The projected classifications of RCC habitat in 2050 were also based on those thresholds. Here, thresholds of habitat suitability were based on the proportion of species present in habitat with different suitability levels. They can also be used as part of the species' biological characteristics of environmental selection in long-term evolution. So, despite having no data for future RCC nesting, our suitability index was applied to future habitat suitability maps.

To examine changes in habitat suitability, we first calculated the proportion of suitable and sub-suitable habitat in the entire area. Then to assess the shift of habitat spatial patterns and fragmentation induced by climate change, we chose suitable habitat, important to species survival to reflect the habitat changes between the present 
and 2050 based on landscape indices (Hirzel et al., 2006). The landscape indices of suitable habitat were calculated for a simple fragmentation assessment included total area, patch number (PN), mean patch size (MPS), largest patch size (LPS), and proportion (\%) of different scales (O’Neill et al., 1988).

\section{RESULTS}

\section{Current RCC habitat, suitability and fragmentation}

Current suitable habitat with climate, vegetation, and environmental variables preferred by RCC was $269,455.6$ ha, which is $9.2 \%$ of the total study area. Most of this suitable habitat was inside Zhalong Reserve (168,950.3 ha accounting for $62.7 \%$ of the total suitable habitat and $71.3 \%$ of the area of the Reserve) (Fig. 2, Tables I and II). Current suitable and sub-suitable habitat accounted for $26.2 \%$ of the total study area, most of which was in Zhalong Reserve and in adjacent areas northwest and southeast of the study area. The largest patch of suitable habitat $(165,085$ ha accounting for $61.3 \%$ of the total suitable habitat) occurred mostly in the Zhalong Reserve, thus strongly supporting the integrity of RCC habitat and the carrying capacity of the Reserve (Table II).
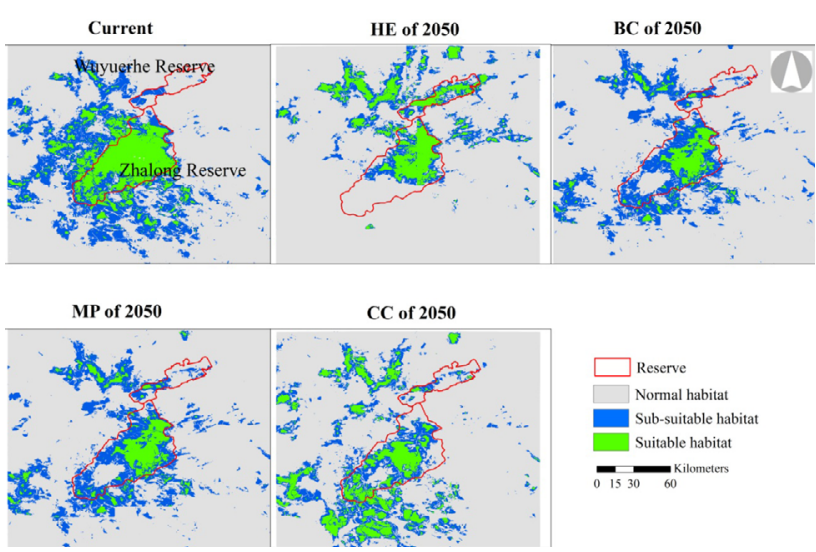

Fig. 2. Current RCC habitat and its suitability to RCC in 2050 , as affected by projected climate change in 4 general circulation models (GCMs) in Zhalong Reserve and the study area. GCM abbreviations: BCC-CSM1-1(BC), CCSM4 (CC), HadGEM2-ES (HE), and MPI-ESM-LR (MP).

Shifts of RCC habitat, suitability, and fragmentation induced by climate change

By 2050 , the proportion of suitable and sub-suitable RCC habitat will decline from $26.2 \%$ to $14.3 \%-19.7 \%$ of the entire study area according to the four GCMs. This means that $6.5 \%-11.8 \%$ of current high quality RCC habitat is predicted to be lost under the impacts of climate change. The HE GCM, rather than the other
GCMs, predicted the greatest loss of RCC habitat, an $11.8 \%$ drop in the proportion of suitable and sub-suitable habitat. Given the climate change, Zhalong Reserve may retain the most projected suitable habitat in 2050, but the proportion of the Reserve's suitable habitat will decrease from its current $71.3 \%$ to $27.3 \%-32 \%$. This shows that $39.3 \%$ - $44 \%$ of current suitable habitat within the Reserve would be lost. Comparatively, the proportional loss of suitable habitat within Zhalong Reserve would be greater than the loss outside the Reserve (Table II). Moreover, we identified a loss of current suitable habitat southeast of Zhalong reserve, and all four GCM scenarios predicted a distinct northward spatial shift of all suitable habitats in 2050 .

According to the predicted increase in $\mathrm{PN}$ coupled with decreases in MPS and LPS, RCC habitat fragmentation, both in the study area and within Zhalong Reserve, will worsen by 2050 because of climate change. With a reduction in the largest patch of current suitable habitat, the study area's ecosystem function and stability, including within the Reserve, will be weakened.

\section{Model validation with variable importance}

Both the training AUC (0.94) and test AUC (0.89) indicated that the results and performance of our model were reliable (Rebelo et al., 2010), and that our assumptions of climatic preferences were accurate and valid. The most important climate variables based on contribution and permutation importance were BIO2: Mean Diurnal Range (max temperature-min temperature) and BIO5: Max Temperature of Warmest Month (Table III). Excepting climate factors, vegetation was the most important habitat variable $(22.9 \%)$ among abiotic and biotic habitat factors, followed by the distance to human communities $(12.9 \%)$ and distance to roads $(8.6 \%)$.

\section{DISCUSSION}

Our study showed that suitable RCC breeding habitat is currently found mainly in the Zhalong Reserve and accounts for $62.7 \%$ of total suitable habitat. The spatial pattern of current suitable habitat not only highlights conservation implications of the Zhalong Reserve for the RCC, but partially explains why RCC population growth remains limited compared to the population sizes of other sympatric cranes, such as the Siberian white crane (Grus leucogeranus) and the hooded crane(Grus monacha), which overall occur in greater numbers than RCC on the Songnen Plain (Su et al., 2000). Because most of the suitable RCC breeding habitat on the Songnen Plain is currently restricted to the Zhalong Reserve (Fig. 2), it has been difficult for the RCC population to expand and grow outside the Reserve. 
Table I. Suitability of RCC habitat showing current and 2050 habitat types and proportions of 4 general circulation models (GCMs) using representative concentration pathway 26 (RCP26) with landscape indices of suitable habitat in study area.

\begin{tabular}{|c|c|c|c|c|c|c|c|c|c|c|c|}
\hline \multirow{4}{*}{$\begin{array}{l}\text { Habitat } \\
\text { type }\end{array}$} & \multirow{3}{*}{$\begin{array}{l}\begin{array}{l}\text { Suitability/ } \\
\text { Fragmentation }\end{array} \\
\text { Suitable habitat (ha) }\end{array}$} & \multirow{3}{*}{$\begin{array}{l}\text { Current } \\
269455.6 \\
\end{array}$} & \multirow[b]{3}{*}{$9.2 \%$} & \multicolumn{8}{|c|}{2050} \\
\hline & & & & \multicolumn{2}{|c|}{$\mathrm{HE}$} & \multicolumn{2}{|c|}{$\mathrm{BC}$} & \multicolumn{2}{|c|}{ MP } & \multicolumn{2}{|c|}{$\mathrm{CC}$} \\
\hline & & & & 180118.6 & $6.1 \%$ & 93225.0 & $3.2 \%$ & 111042.6 & $3.8 \%$ & 213138.3 & $7.3 \%$ \\
\hline & Sub-suitable habitat (ha) & 499969.9 & $17.0 \%$ & 241462.8 & $8.2 \%$ & 384435.8 & $13.1 \%$ & 408809.4 & $13.9 \%$ & 365039.1 & $12.4 \%$ \\
\hline \multirow{5}{*}{$\begin{array}{l}\text { Suitable } \\
\text { habitat }\end{array}$} & Normal habitat (ha) & 2168700.7 & $73.8 \%$ & 2516544.7 & $85.7 \%$ & 2460465.4 & $83.7 \%$ & 2418274.1 & $82.3 \%$ & 2359948.8 & $80.3 \%$ \\
\hline & Patch number (PN) & 1267 & & 928 & & 555 & & 611 & & 1339 & \\
\hline & Mean patch size (MPS) & 212.7 & & 194.1 & & 168.1 & & 181.7 & & 159.1 & \\
\hline & Largest patch size (LPS) & 165085 & & 67041.2 & & 43258.6 & & 49481.7 & & 37712.7 & \\
\hline & $\begin{array}{l}\text { Proportion of LPS in } \\
\text { total suitable habitat }\end{array}$ & & $61.3 \%$ & & $37.2 \%$ & & $46.4 \%$ & & $44.6 \%$ & & $17.7 \%$ \\
\hline
\end{tabular}

GCM abbreviations: BCC-CSM1-1(BC), CCSM4 (CC), HadGEM2-ES (HE), and MPI-ESM-LR (MP).

Table II. Proportions and landscape indices of suitable habitat now and in 2050 according to 4 GCMs in Zhalong Reserve.

\begin{tabular}{|c|c|c|c|c|c|}
\hline \multirow[t]{2}{*}{ Area, proportion, landscape indices } & \multirow[t]{2}{*}{ Current } & \multicolumn{4}{|c|}{2050} \\
\hline & & HE & BC & MP & $\mathbf{C C}$ \\
\hline Total area (TA, ha) & 168950.3 & 75769.2 & 64628.3 & 75333.6 & 67697.3 \\
\hline Proportion in total suitable habitat & $62.7 \%$ & $42.1 \%$ & $69.3 \%$ & $65.4 \%$ & $31.8 \%$ \\
\hline Proportion in area of reserve & $71.3 \%$ & $32.0 \%$ & $27.3 \%$ & $31.8 \%$ & $28.6 \%$ \\
\hline Patch number (PN) & 286 & 148 & 204 & 165 & 265 \\
\hline Mean patch size (MPS, ha) & 590.7 & 511.9 & 316.8 & 456.6 & 255.5 \\
\hline Largest patch size (LPS, ha) & 137511.0 & 66212.2 & 43239.6 & 62671.3 & 37712.7 \\
\hline Proportion of LPS in total suitable Reserve habitat & $81.4 \%$ & $87.4 \%$ & $66.9 \%$ & $83.2 \%$ & $55.7 \%$ \\
\hline
\end{tabular}

GCM abbreviations: BCC-CSM1-1(BC), CCSM4 (CC), HadGEM2-ES (HE), and MPI-ESM-LR (MP).

The people interviewed outside the Reserve confirmed that there were few RCCs in each non-reserve RCC population. Our study demonstrated that temperature, rather than precipitation, was the more important variable and a valuable contributor to modeling permutations (Table III). The importance of temperature in our models supported greater avian sensitivity to temperature than to precipitation (Pearce-Higgins et al., 2015). Also, other studies have identified temperature as some species' dominant abiotic factor affecting behavior, incubation, and mortality (Paladino, 1985; Bale et al., 2002; Long et al., 2012).

Global temperatures have increased by $0.75{ }^{\circ} \mathrm{C}$ in the past 100 years and rates of future climate changes are projected to increase through the 21st century (Hole et al., 2009). According to the climate change projection for our study area in northeast China, both temperature and precipitation will increase (Zhao, 2007). The projected northward shift of RCC habitat from the Zhalong Reserve in several of our climate scenarios agrees with general projections for avian species to move northward because of climate change (Thomas and Lennon, 1999; Sparks and Braslavská, 2001; Parmesan, 2007). In addition, with the predicted reduction in suitable habitat and increased habitat fragmentation (Table I), habitat suitability and carrying capacity of this ecosystem will likely be affected. Since most high-quality habitat is currently located within Zhalong Reserve, the impacts of climate change on the Reserve are expected to be much more significant than on other parts of the study area. Coupled with the current design of protected areas within the study area, an obvious spatial mismatch between suitable habitat distribution and the Reserve network could develop by 2050 . Since there would be a gap of protected area in the northwest of the study area, priority should be given to the establishment of a new reserve in that area to accommodate future suitable 
Table III. Bioclimatic and habitat variables, their contribution, and percent permutation importance in Maxent habitat modeling. Habitat variables and descriptions were taken from Worldclim (www.worldclim.org/bioclim).

\begin{tabular}{|c|c|c|c|}
\hline $\begin{array}{l}\text { Habitat } \\
\text { variables }\end{array}$ & Description & $\begin{array}{l}\text { Variable } \\
\text { contribution (\%) }\end{array}$ & $\begin{array}{l}\text { Permutation } \\
\text { importance (\%) }\end{array}$ \\
\hline $\mathrm{BIO} 1$ & Annual mean temperature & 6.7 & 6.1 \\
\hline $\mathrm{BIO} 2$ & Mean diurnal range (mean of monthly (max temp-min temp)) & 23.6 & 13.9 \\
\hline $\mathrm{BIO} 3$ & Isothermality $(\mathrm{BIO} 2 / \mathrm{BIO} 7)(* 100)$ & 0.2 & 4.2 \\
\hline $\mathrm{BIO} 4$ & Temperature seasonality (standard deviation $* 100$ ) & 4.5 & 2.5 \\
\hline $\mathrm{BIO5}$ & Max temperature of warmest month & 1.3 & 13.2 \\
\hline $\mathrm{BIO6}$ & Min temperature of coldest month & 0.1 & 0.5 \\
\hline $\mathrm{BIO} 7$ & Temperature annual range (BIO5-BIO6) & 0.3 & 0.3 \\
\hline $\mathrm{BIO} 8$ & Mean temperature of wettest quarter & 0.5 & 0.4 \\
\hline $\mathrm{BIO} 9$ & Mean temperature of driest quarter & 0.0 & 0.1 \\
\hline $\mathrm{BIO} 10$ & Mean temperature of warmest quarter & 0.7 & 3.5 \\
\hline BIO11 & Mean temperature of coldest quarter & 1.2 & 0.0 \\
\hline $\mathrm{BIO} 12$ & Annual Precipitation & 1.0 & 0.1 \\
\hline $\mathrm{BIO} 13$ & Precipitation of wettest month & 0.1 & 6.9 \\
\hline $\mathrm{BIO} 14$ & Precipitation of driest month & 0.3 & 0.0 \\
\hline BIO15 & Precipitation seasonality (coefficient of variation) & 2.1 & 0.0 \\
\hline $\mathrm{BIO} 16$ & Precipitation of wettest quarter & 0.0 & 0.0 \\
\hline $\mathrm{BIO} 17$ & Precipitation of driest quarter & 3.5 & 6.2 \\
\hline $\mathrm{BIO} 18$ & Precipitation of warmest quarter & 1.7 & 0.6 \\
\hline BIO19 & Precipitation of coldest quarter & 1.6 & 1.4 \\
\hline Community & Distance to community & 12.9 & 18.4 \\
\hline Lake & Distance to lake & 4.4 & 8.4 \\
\hline Elevation & Height above sea level & 1.0 & 0.2 \\
\hline River & Distance to river & 1.0 & 5.3 \\
\hline Road & Distance to road & 8.6 & 4.0 \\
\hline Vegetation & Vegetation type & 22.9 & 4.0 \\
\hline
\end{tabular}

or sub-suitable habitat arising from climate change (Fig. 2). Additionally, wetland rehabilitation programs, such as Phragmites planting, should be started now to proactively create future habitat on the Songnen Plain.

An additional impending threat to local RCC habitat may be, because of an increasing demand for food, an increase in grain production that could happen at any time and that would potentially raise ambient temperatures by increasing $\mathrm{CO}_{2}$ and $\mathrm{CH} 4$ emissions due to land use changes and fertilizer use (Guo et al., 2017). To protect RCC habitat and to restrict $\mathrm{CO} 2$ and $\mathrm{CH} 4$ emissions, thus also mitigating the scale of climate change, transformation of wetland into crop lands must be avoided. Technically, since rice cultivation requires abundant water during its planting cycle, its area of cultivation should be controlled or decreased. To reduce future temperature increases, soybeans, because of their notable $\mathrm{CO}_{2}$ sink and low water requirements, should have planting priority and should replace rice production in this area (Jin and Zhu, 2008). Organic agriculture practices would partially reduce the scale of temperature increases because they require less fertilizer and mulch film (Zhang et al., 2008). Indeed, such practices should become the region's future cultivation model.

Because of the RCC's fidelity to their home range (Zou and Wu, 2009; Brown, 1969), our presence data based on nest locations was reliable for modeling, as validated by the high AUC value. While we included temperature and precipitation as variables in our study, we recognized that the impacts of other climatic factors, such as relative humidity, wind velocity, and sunshine duration, are factors deserving investigation in climate change projections. We 
encourage subsequent studies to continue long-term climate monitoring and data accumulation and to investigate RCC spatial utilization, thus securing a more robust projection of climate change. Moreover, we noted that the hydrological variables of our study were represented roughly by the land covered by rivers and lakes. Since water is key to the function and dynamics of wetland ecosystems, and water levels should be considered indicators of good breeding environments (Boyce et al., 2005), further study should incorporate more hydrological factors, (e.g. $\mathrm{pH}$ levels, water depth, and turbidity) in habitat projections.

\section{ACKNOWLEDGEMENTS}

This study was funded by Fundamental Research Funds of CAF (No. CAFYBB2016MA010) and the National Key Research and Development Program of China (No. 2016YFC0500404). The GPS collars used in our study were provided by the World Wildlife Fund-China. We also acknowledge the Zhalong National Nature Reserve staff who were involved in RCC field monitoring from 2014 2017.

\section{Disclosure statement}

The authors declare that there are no conflicts of interest regarding the publication of this article.

\section{REFERENCES}

Bale, J.S., Masters, G.J., Hodkinson, I.D., Awmack, C., Bezemer, T.M., Brown, V.K., Butterfield, J., Buse, A., Coulson, J.C. and Farrar, J., 2002. Herbivory in global climate change research: Direct effects of rising temperature on insect herbivores. Glob. Change Biol., 8: 1-16. https://doi.org/10.1046/ j.1365-2486.2002.00451.x

Bitterlin, L.R. and Buskirk, J.V., 2014. Ecological and life history correlates of changes in avian migration timing in response to climate change. Clim. Res., 61: 109-121. https://doi.org/10.3354/cr01238

Both, C., Asch, M.V., Bijlsma, R.G., Burg, A.B.V.D. and Visser, M.E., 2009. Climate change and unequal phenological changes across four trophic levels: Constraints or adaptations? J. Anim. Ecol., 78: 73. https://doi.org/10.1111/j.1365-2656.2008.01458.x

Boyce, M.S., Lele, S.R. and Johns, B.W., 2005. Whooping crane recruitment enhanced by egg removal. Biol. Conserv., 126: 395-401. https://doi.org/10.1016/j. biocon.2005.06.011

Brook, B.W., 2008. Synergies between climate change, extinctions and invasive vertebrates. Wildl. Res., 35: 249-252. https://doi.org/10.1071/WR07116
Brown, J., 1969. Territorial behavior and population regulation in territorial birds: A review and reevaluation. Wilson Bull., 81: 293-329.

Chen, L. and Zhao, X., 2008. Research on ecological restoration of Zhalong wetland. Environ. Sci. Manage., 33:145-146.

Crabtree, D. and Ellis, C.J., 2010. Species interaction and response to wind speed alter the impact of projected temperature change in a montane ecosystem. $J$. Veget. Sci., 21: 744-760. https://doi.org/10.1111/ j.1654-1103.2010.01184.x

Dan, L.W. and Seifert, S.N., 2011. Warren dl, seifert sn. Ecological niche modelling in maxent: The importance of model complexity and the performance of model selection criteria. Ecological applications. Ecol. Appl., 21: 335-342. https://doi. org/10.1890/10-1171.1

Gallagher, R.V., Hughes, L. and Leishman, M.R., 2013. Species loss and gain in communities under climate change: Consequences for functional diversity. Ecography, 36: 531-540. https://doi.org/10.1111/ j.1600-0587.2012.07514.x

Geospatial data cloud, 2018. DEM data. http://www. gscloud.cn.

Gong, M., Guan, T., Hou, M., Liu, G. and Zhou, T., 2016. Hopes and challenges for giant panda conservation under climate change in the qinling mountains of china. Ecol. Evol., 7: 596-605. https://doi. org/10.1002/ece3.2650

Guo, J., Song, Z., Zhu, Y., Wei, W., Li, S. and Yu, Y., 2017. The characteristics of yield-scaled methane emission from paddy field in recent 35-year in China: A meta-analysis. J. Clean. Prod., 161: 1044 1050. https://doi.org/10.1016/j.jclepro.2017.06.073

Hedenström, A., 2006. Scaling of migration and the annual cycle of birds. Ardea Wageningen, 94: 399408.

Heimonen, K., Valtonen, A., Kontunen-Soppela, S., Keski-Saari, S., Rousi, M., Oksanen, E. and Roininen, H., 2015. Insect herbivore damage on latitudinally translocated silver birch (Betula pendula) - predicting the effects of climate change. Clim. Change, 131: 1-13. https://doi.org/10.1007/ s10584-015-1392-4

Hijmans, R.J., Cameron, S.E., Parra, J.L., Jones, P.G. and Jarvis, A., 2005. Very high resolution interpolated climate surfaces for global land areas. Int. J. Climatol., 25: 1965-1978. https://doi.org/10.1002/ joc. 1276

Hirzel, A.H., Lay, G.L., Helfer, V., Randin, C. and Guisan, A., 2006. Evaluating the ability of habitat suitability models to predict species presences. Ecol. 
Modell., 199: 142-152. https://doi.org/10.1016/j. ecolmodel.2006.05.017

Hole, D.G., Willis, S.G., Pain, D.J., Fishpool, L.D., Butchart, S.H.M., Collingham, Y.C., Rahbek, C. and Huntley, B., 2009. Projected impacts of climate change on a continent-wide protected area network. Ecol. Lett., 12: 420-431. https://doi.org/10.1111/ j.1461-0248.2009.01297.x

Hong, Y., Nix, H.A., Hutchinson, M.F. and Booth, T.H., 2005. Spatial interpolation of monthly mean climate data for china. Int. J. Climatol., 25: 1369-1379. https://doi.org/10.1002/joc.1187

Huang, Q., Sauer, J.R. and Dubayah, R.O., 2017. Multidirectional abundance shifts among north american birds and the relative influence of multifaceted climate factors. Glob. Chang. Biol., 23: 3610-3622. https://doi.org/10.1111/gcb.13683

IUCN, 2012. The IUCN red list of threatened species. Version 2012.1. http://www.iucnredlist.org. (Accessed on 25 September 2012).

Jin, Z.Q. and Zhu, D.W., 2008. Impacts of changes in climate and its variability on food production in northeast china. Acta Agron. Sin., 34: 1588-1597. https://doi.org/10.1016/S1875-2780(09)60005-5

Johnsgard, P.A., 1983. Cranes of the world. Indiana University Press.

Lehikoinen, A., Saurola, P., Byholm, P., Lindén, A. and Valkama, J., 2010. Life history events of the eurasian sparrowhawk accipiter nisus in a changing climate. J. Avian Biol., 41: 627-636. https://doi.org/10.1111/ j.1600-048X.2010.05080.x

Li, F. and Yang, H., 1999. The nest-site selection by redcrowned crane in the zhalong wetland. J. Northeast For. Univ., 6: 38-42.

Li, R., Xu, M., Wong, M.H.G., Qiu, S., Sheng, Q., Li, X. and Song, Z., 2014. Climate change-induced decline in bamboo habitats and species diversity: Implications for giant panda conservation. Divers. Distrib., 21: 379-391. https://doi.org/10.1111/ ddi. 12284

Li, W. and Zhao, H., 1991. A preliminary study on ecological biology of the red crowned cranes in the xingkai lake natural protected area. J. Heilongjiang August First Land Reclam. Univ., 1:67-76.

Li, H. and Xiao, Y.U., 2015. Population issues and its social economic effects in northeast China. Northeast Asia Forum, 5: 118-126.

Liu, Z., Li and Yang, T.G., 2008. Introduction of the professional interpolation software for meteorology data:Anusplinn. Meteorol. Mon., 34: 92-100.

Long, Y., Hu, C., Shi, B., Yang, X. and Hou, M., 2012. Effects of temperature on mate location in the planthopper, Nilaparvata lugens (homoptera: Delphacidae). Environ. Ent., 41: 1231. https://doi. org/10.1603/EN12143

Ma, Z., Bo, L., Li, W., Han, N., Chen, J. and Andrewr, W., 2009. Conflicts between biodiversity conservation and development in a biosphere reserve. J. appl. Ecol., 46: 527-535. https://doi.org/10.1111/j.13652664.2008.01528.x

Ma, Z. and Tang, Z.W.H., 1998. History of red-crowned crane Grus japonensis and its habitats in China. Bird Conserv. Int., 8: 11-18. https://doi.org/10.1017/ S0959270900003592

Masatomi, H., Momose, K., Matsuo, T., Koga, K., Matsumoto, F., Aoki, N. and Tomiyama, N., 2001. Breeding status of the tancho Grus japonensis in Eastern Hokkaido in spring of 2001. J. environ. Sci. Lab. Senshu Univ. (Japan), 8: 155-180.

Masatomi, Y., Higashi, S. and Masatomi, H., 2007. A simple population viability analysis of tancho (Grus japonensis) in Southeastern Hokkaido, Japan. Popul. Ecol., 49: 297-304. https://doi.org/10.1007/ s10144-007-0048-2

Nakićenović and Nebojša, 2000. Special report on emissions scenarios. Cambridge University Press.

O’Neill, R.V., Krummel, J.R., Gardner, R.H., Sugihara, G., Jackson, B., Deangelis, D.L., Milne, B.T., Turner, M.G., Zygmunt, B. and Christensen, S.W., 1988. Indices of landscape pattern. Lands. Ecol., 1: 153-162. https://doi.org/10.1007/BF00162741

Paladino, F.V., 1985. Temperature effects on locomotion and activity bioenergetics of amphibians, reptiles, and birds. Am. Zool., 25: 965-972. https://doi. org/10.1093/icb/25.4.965

Parmesan, C., 2006. Ecological and evolutionary responses to recent climate change. Annu. Rev. Ecol. Evol. Syst., 37: 637-669. https://doi.org/10.1146/ annurev.ecolsys.37.091305.110100

Parmesan, C., 2007. Influences of species, latitudes and methodologies on estimates of phenological response to global warming. Glob. Change Biol., 13: $1860-1872$. https://doi.org/10.1111/j.13652486.2007.01404.x

Parry, M.L., Canziani, O.F., Palutikof, J.P., Linden, P.J.V.D. and Hanson, C.E., 2011. Climate change 2007: Impacts, adaptation and vulnerability. Contribution of working group ii to the fourth assessment report of the intergovernmental panel on climate change. Summary for policymakers. Astron. Nachr., 332: 697-705.

Peñuelas, J. and Filella, I., 2001. Responses to a warming world. Science, 294: 793-795. https://doi. org/10.1126/science. 1066860 
Pearce-Higgins, J.W., Eglington, S.M., Martay, B. and Chamberlain, D.E., 2015. Drivers of climate change impacts on bird communities. J. Anim. Ecol., 84: 943954. https://doi.org/10.1111/1365-2656.12364

Peacock, S., 2011. Projected 21st century climate change for wolverine habitats within the contiguous united states. Environ. Res. Lett., 6: 14007-14015(14009). https://doi.org/10.1088/1748-9326/6/1/014007

Phillips, S.J., 2008. Transferability, sample selection bias and background data in presence-only modelling: A response to Peterson et al., (2007). Ecography, 31:272278. https://doi.org/10.1111/j.0906-7590.2008.5378.x

Phillips, S.J. and Dudík, M., 2008. Modeling of species distributions with maxent: New extensions and a comprehensive evaluation. Ecography, 31: 161175. https://doi.org/10.1111/j.0906-7590.2008.5203.x

Ramsar, 2018. The Ramsar sites of China. https://rsis. ramsar.org/ris-search/ (Accessed 10 August, 2018)

Rebelo, H., Tarroso, P. and Jones, G., 2010. Predicted impact of climate change on european bats in relation to their biogeographic patterns. Glob. Change Biol., 16: 561576. https://doi.org/10.1111/j.1365-2486.2009.02021.x

Roberts, D.R., Nielsen, S.E. and Stenhouse, G.B., 2014. Idiosyncratic responses of grizzly bear habitat to climate change based on projected food resource changes. Ecol. appl. Publ. Ecol. Soc. Am., 24: 11441154. https://doi.org/10.1890/13-0829.1

Rubolini, D., Saino, N. and Møller, A.P., 2010. Migratory behaviour constrains the phenological response of birds to climate change. Clim. Res., 42: 45-55. https:// doi.org/10.3354/cr00862

Santangeli, A., Rajasärkkä, A. and Lehikoinen, A., 2016. Effects of high latitude protected areas on bird communities under rapid climate change. Glob. Change Biol., 23: 2241-2249. https://doi.org/10.1111/ gcb. 13518

Sparks, T.H. and Braslavská, O., 2001. The effects of temperature, altitude and latitude on the arrival and departure dates of the swallow Hirundo rustica in the Slovak Republic. Int. J. Biometeorol., 45: 212-216. https://doi.org/10.1007/s004840100095

State Forestry Administration (SFA), 2014. The second national survey report for wetland in China. (Announced but not published; In Chinese), Beijing.

Su, H., Lin, Y., Li, D. and Qian, F., 2000. Status of chinese cranes and their conservation strategies. Chin. Biodivers., 8: 180-191.

Su, L. and Zhou. H., 2012. Status, threats and conservation needs for the continental population of the red-crowned crane. Chin. Birds, 3:147-164. https://doi.org/10.5122/ cbirds.2012.0030

Takuji, U., Butchart, S.H.M. and Phillimore, A.B., 2016.
Temporal shifts and temperature sensitivity of avian spring migratory phenology: A phylogenetic metaanalysis. J. Anim. Ecol., 86: 250-261. https://doi. org/10.1111/1365-2656.12612

Thackeray, S.J., Sparks, T.H., Frederiksen, M., Burthe, S., Bacon, P.J., Bell, J.R., Botham, M.S., Brereton, T.M., Bright, P.W. and Carvalho, L., 2010. Trophic level asynchrony in rates of phenological change for marine, freshwater and terrestrial environments. Glob. Change Biol., 16: 3304-3313. https://doi.org/10.1111/j.13652486.2010.02165.x

Thomas, C.D. and Lennon, J.J., 1999. Birds extend their ranges northwards. Nature, 399: 213-213. https://doi. org/10.1038/20335

Tuanmu, M.N., Viña, A., Winkler, J.A., Li, Y., Xu, W., Ouyang, Z. and Liu, J., 2013. Climate-change impacts on understorey bamboo species and giant pandas in China Qinling mountains. Nat. Clim. Change, 3: 249253. https://doi.org/10.1038/nclimate 1727

Wang, W., 2011. Investigations of population size and conservation measures for red-crowned crane in Zhalong Natural Reserve. Chinese J. Wildl., 32: 80-82.

Wang, Z., Li, Z., Beauchamp, G. and Jiang, Z., 2011. Flock size and human disturbance affect vigilance of endangered red-crowned cranes (Grus japonensis). Biol. Conserv., 144: 101-105. https://doi.org/10.1016/j. biocon.2010.06.025

Wood, L.J. and Dragicevic, S., 2007. Gis-based multicriteria evaluation and fuzzy sets to identify priority sites for marine protection. Biodivers. Conserv., 16: 2539-2558. https://doi.org/10.1007/s10531-006-9035-8

World Clim, 2018. Future climate data. http://www. worldclim.com/CMIP5v1. (Accessed 10 August, 2018)

$\mathrm{Xu}, \mathrm{W}$, 2009. Integrating population size analysis into habitat suitability assessment: Implications for giant panda conservation in the Minshan Mountains, China. Ecol. Res., 24: 1101-1109. https://doi.org/10.1007/ s11284-009-0589-2

Zhang, D., Chi, B., Huang, X., Liu, S. and Zhang, J., 2008. Analysis of adverse effects on maize yield decrease resulted from plastic film mulching in dryland. Trans. Chinese Soc. Agric. Eng., 24: 99-102.

Zhang, H., Fu, Q. and Lin, J., 2012. Horizontal spatial variation of soil arsenic in Northern Songnen plain. $J$. Northeast For. Univ., 40: 108-111.

Zhao, Z., 2007. Projections of climate change over northeastern China for the 21st century. J. Meteorol. Environ., 23: 1-4.

Zou, H.F. and Wu, Q.M., 2009. Internal distribution pattern of the nests and home ranges of red-crowned cranes in Zhalong Nature Reserve. Acta Ecol. Sin., 29: 17101718 . 